\title{
Corneal astigmatism in applanation tonometry
}

\begin{abstract}
Purpose This short study aims at quantitatively correlating scale readings of the Goldmann tonometer to corneal curvatures in one and the same eye.

Methods A total of 30 eyes of 21 adult patients who presented themselves in clinical practice for routine examination were arbitrarily selected. Corneal curvatures were measured in the horizontal and vertical meridians and then applanation tension measured in the same order. The data were submitted to statistical analysis by computer using Microsoft Excel and SAS System programs.
\end{abstract}

Results All cases exhibited a strong positive correlation of tonometric readings to corneal curvature, that is, the flatter the curvature, the lower the reading on the scale of the tonomer, and vice versa.

Conclusion The numbers on the scale of the Goldmann tonometer may not represent true intraocular pressure in $\mathrm{mmHg}$ because their values depend on a number of variables of the globe, including corneal astigmatism. Attention to these influences may help interpret the tonometric record in difficult cases.

Eye (2003) 17, 617-618. doi:10.1038/

sj.eye. 6700417

Keywords: intraocular pressure; glaucoma; tonometry; goldmann tonometer; cornea; astigmatism

\section{Introduction}

In the 50 years since Hans Goldmann invented his applanation tonometer, ${ }^{1}$ it has justifiably become the standard instrument in practice and the touchstone for other tonometers. ${ }^{2,3}$

Goldmann believed that as long as the applanated area had a diameter of $3.06 \mathrm{~mm}$ (area of $7.354 \mathrm{~mm}^{2}$ ) normal corneal variations in man did not influence the instrument's reading: 'It does not make any difference if the cornea is
$\mathrm{HH}$ Mark $^{1}$ and TL Mark ${ }^{2}$

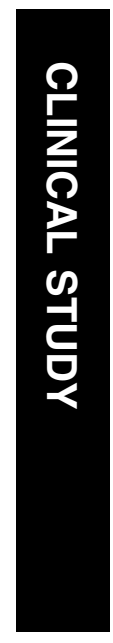

more curved or less, or if the eye has a higher or lower rigidity'. ${ }^{4,5}$

Since then, however, it has been shown that the tonometer's recordings are affected by a number of normal variations of the globe, such as corneal thickness, ${ }^{6}$ corneal curvature, ${ }^{7}$ and axial length. ${ }^{8}$ It therefore seemed useful to quantify also the relation of the tonometer's values to corneal astigmatism with a view to a better definition of its limitations, ${ }^{9}$ thereby rendering the interpretation of its record more accurate. We have chosen to do the measurements in one and the same eye in order to eliminate the effect of dependent and independent variables of different globes.

\section{Material and methods}

A total of 30 eyes of 21 adult patients who came in for routine examination were selected randomly for measurement. The sample size was deemed adequate when preliminary analysis revealed a strong and very significant correlation of the data. None of the subjects had any active ocular disease or abnormalities of the coats. A starting point of $1.75 \mathrm{D}$ of regular astigmatism was chosen. In all, 22 eyes had astigmatism with the rule, and eight against it. One investigator did all the measurements and two others then independently analysed the data by computer, using mainly Microsoft Excel and SAS System programs.

\section{Results}

The average astigmatism in our population was 3.3 D, and the average difference in tonometry in the two meridians was 2.8 scale units. The results of the coupled measurements are shown in Figure 1. In each of the eyes, the tonometric pressure value was higher when the prisms were at the steeper corneal meridian than at the flatter. Correlation coefficient was 0.61 (covarriance $=112.6$ ) with an $r^{2}=37$, indicating that $37 \%$ of the difference in tonometric data was determined solely by corneal astigmatism.
${ }^{1} 2$ Church Street South New Haven

CT 06519-1717, USA

${ }^{2}$ The MedStat Group ${ }^{\circledR}$ Washington, DC, USA

Correspondence:

HH Mark

2 Church Street South New Heaven

CT 06519-1717, USA

Tel: + 12038651010

Fax: + 12032346778

E-mail: iimd@ aol.com

Received: 16 January 2002 Accepted in revised form: 26 September 2002 


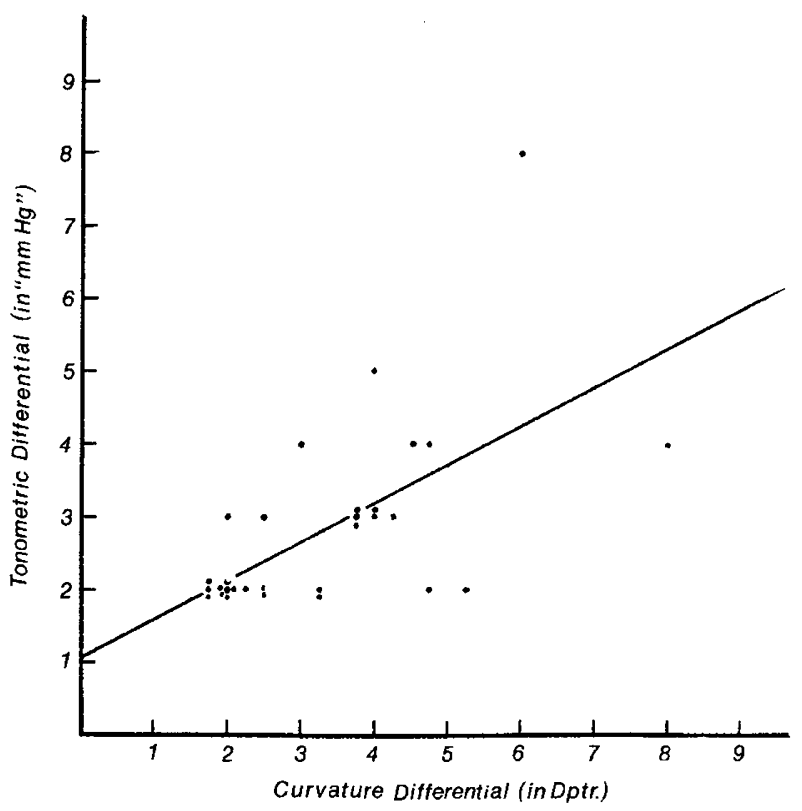

Figure 1 Correlation of tonometer reading to astigmatism $(n=30)$.

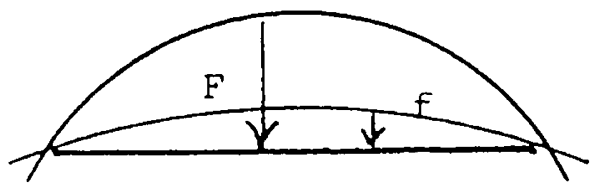

Figure 2 Applanation forces $v s$ curvature.

In linear regression analysis in which tension was the dependent variable and curvature the independent one, the slope coefficient was $0.53+0.13(\mathrm{SE})$ indicating that for these data, an increase of $1 \mathrm{D}$ in corneal curvature corresponded to an increase of 0.53 units (' $\mathrm{mmHg}^{\prime}$ ) in the tonometer's scale value. The coefficient was statistically significant $(P=0.004)$. The physical forces are illustrated in Figure 2.

\section{Discussion}

The crux of Goldmann tonometry is the premise that when an area of exactly $3.06 \mathrm{~mm}$ in diameter $\left(7.354 \mathrm{~mm}^{2}\right)$, in the centre of the human cornea, is applanated, the true intraocular pressure (IOP) underneath it is measured. ${ }^{10}$ Goldmann and Theo Schmidt recognized the problem of an astigmatic cornea, where the area is an ellipse with different diameters in different meridians; the end point of the prism's semicircles is therefore reached sooner in the flatter than in the steeper one. They believed to have overcome the dilemma by calculating the angle to the horizontal where the applanated area of an ellipse will be exactly $7.354 \mathrm{~mm}^{2}$. This was found to be $43^{\circ}$, and it is notched in the casing of the tonometer's prism.

Alternatively, one may simply average the readings of the two meridians.

Actual quantitative data of the difference in scale reading in different meridians were never published, leaving the magnitude of the error unknown. This study therefore aimed at filling the void on the way to improved interpretation of the tonometer's record. Corneal astigmatism of 5-6D is not quite rare, and could make the difference, for instance, between 18 and 21 ' $\mathrm{mmHg}$ ', which in turn may decide the management of the patient. In the final analysis, all methods that attempt to find the true IOP by pressing on the eyeball from outside are subject to extraneous influences that render them inaccurate, militating against replacing hard clinical judgement with mathematical calculations and an 'Imbert-Fick Law'. ${ }^{11,12}$

\section{Acknowledgement}

The kind assistance of the staff of the Yale University Medical Library is gratefully acknowledged.

\section{References}

1 Goldmann H. Un neuveau tonometre. Bull Soc Ophthalmol France 1955; 67: 474-475.

2 Iester M, Mermoud A, Achache F, Roy S. New TonoPen XL: comparison with the Goldmann tonometer. Eye 2001; 15: 52-58.

3 Troost R, Vogel A, Beck S, Schwenn O, Grus F, Pfeiffer N. Clinical comparison of two intraocular pressure measurement methods: SmartLens versus Goldmann. Graefes Arch Ophthalmol 2001; 239(12): 905-909.

4 Goldmann H. Applanation tonometry. In: Newell FW (ed). Glaucoma second conference. J Macy Jr Foundation: New York, 1956, pp 167-220.

5 Goldmann H, Schmidt T. Ueber Applanationstonometrie. Ophthalmologica 1957; 134: 225-242.

6 Ehlers N, Bramsen T, Sperling S. Applanation tonometry and central corneal thickness. Acta Ophthalmol (Copenh) 1975; 53: 34-43.

7 Mark H. Corneal curvature in applanation tonometry. Am J Ophthalmol 1973; 76: 223-224.

8 Mark H, Robbins KP, Mark TL. Axial length in applanation tonometry. J Cataract Refract Surg 2002; 28: 504-506.

9 Smith P. Limitations of the tonometer. Ophthalmol Rev 1915; 34: 65-69.

10 Schmidt T. Zur Applanationstonometrie an der Spaltlampe. Ophthalmologica 1957; 133: 337-342.

11 Markiewitz HH. The so-called Imbert-Fick law. Arch Ophthalmol 1960; 64: 159.

12 Gloster J, Perkins ES. The validity of the Imbert-Fick law as applied to applanation tonometry. Exp Eye Res 1963; 2: 274-277. 